\title{
The b-value of the Kelud Volcano in the Last Three Decades
}

\author{
Sintia Windhi Niasari ${ }^{1 *}$, Lusia Rita Nugraheni ${ }^{2}$, and Puspita Dian Maghfira ${ }^{2}$ \\ ${ }^{1}$ Physics Department, Faculty of Mathematics and Natural Sciences, UGM, 55281 Yogyakarta, Indonesia \\ ${ }^{2}$ Geological Engineering Department, Faculty of Engineering, UGM, 55281 Yogyakarta, Indonesia
}

\begin{abstract}
Kelud volcano is located in the Kediri sub-district, East Java Province, Indonesia. This volcano is still active, with total population, in the radius of $10 \mathrm{~km}$, is around 10 thousand people. Kelud volcano is a popular tourist destination. On the weekend, total visitor can reach 5,000 people per-day. These people are at high risk when the Kelud volcano erupts. The last eruption of the Kelud volcano occurred in 2014 and was explosive eruption. Previously, there was an effusive eruption in 2007. These two types of eruption have its own geo hazard risk. Thus, predict the eruption type could help hazard mitigation. In this study, two data sets of earthquakes, 1990-2007 and 2008-2020, were analysed to determine the b-value and its relationship to the eruption type of the Kelud volcano. The calculation of the b-value uses the GutenbergRichter relationship. Calculation of the b-value in 2007, when there was an effusive eruption, showed a value of 2.27, while in 2014 (when there was an explosive eruption) was 1.85. After 2009, the curve of the b-value against time shows decrease. As a long term precursor of the Kelud activity, this b-value curve should be analysed continuously, besides volcano tectonic seismicity monitoring.
\end{abstract}

\section{Introduction}

Kelud volcano is an active volcano which has an altitude of 1731 m.a.s.l. This active volcano is located in Kediri, East Java, Indonesia (Figure 1). Total population, in the radius of $10 \mathrm{~km}$, is around 10 thousand people. Additionally, Kelud volcano is a popular destination in East Java Province, where up to ten thousand people visit this tourist destination on the weekend.

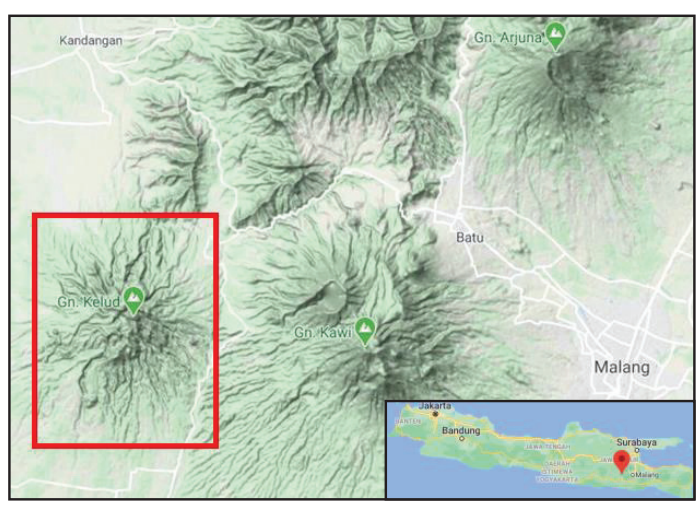

Fig. 1. Kelud volcano location.

The Kelud volcano is an active and dangerous volcano in Indonesia with eight eruptions of VEI 4 (Volcano Eruption Index scale of 5) [1]. This volcano is a result of Australian plate subduction beneath Eurasian plate. The subduction produces magma, from partial melting, that moves upward to the surface through weak zone, such as fault. Before the volcano erupts, magma migrates through conduit from magma chamber. If the magma contains high dissolve gasses, then effusive eruption occur [2]. In the contrary, when the magma is more viscous, pressure may build up and resulted in explosive eruption.

Kelud volcano eruption type consists of both explosive and effusive [1]. Centre of Volcanology and Geological Hazard Mitigation reported 33 eruption of the Kelud volcano [1]. The first eruption was on 1000, while the last eruption was on February 13, 2014.

An explosive eruption was occurred on 10 February 1990 [1]. An effusive eruption on 3 November 2007 was forming a lava dome in the crater [1]. And then, a large explosion took place in the evening of 13 February 2014, destroying the 2007 lava dome [3].

Both eruptions in 2007 and 2014 have similar precursory seismicity, but the depth range and the magnitude are different [1]. The depth range of VT for 2007 eruption was $1-2 \mathrm{~km}$, while on the 2014 eruption was about $0-4 \mathrm{~km}$. The magnitudes of VTs in 2007 are generally smaller than 2014 .

The b-value is the seismotectonic parameter of an area and shows the relative number of small and large earthquake [4]. The b-value has been studied for long- to short-term predictions of future earthquakes [5]. The bvalue decreases before large earthquakes [6].

The USGS earthquake data catalog around the Kelud volcano, with the event period from 1973 until 1990 and 1990-2007, were used to identify any correlation between $b$ value variations of the Gutenberg-Richter law with the eruption type [7]. The first data set (1973 1990), which connecting to the explosive erupion in 1990, showed low b-value of 0.9 . The other data set $(1990$ - 2007), related to effusive eruption in 2007, resulted in b-value of 1.0. The authors conlcuded that

*Corresponding author: sintia_windhi@ugm.ac.id 
low b-value prior to the explosive eruption of 1990 is described as a symptom of stress build-up accompanied by a symptom of increased speed due to the emergence and development of cracks.

The $b$ value variations can be a good indicator of the state of the volcano and an efficient long term precursor [8]. Thus, in this study, two data sets of earthquakes, 1990-2007 and 2008-2020, were analysed to determine the $b$-value and its relationship to the eruption type of the Kelud volcano. We proposed that the b-value of explosive eruption in 2014 is lower than the b-value of effusive eruption in 2007.

\section{Methods}

The data used in this study were from the USGS earthquake catalog

(https://earthquake.usgs.gov/earthquakes/search/). The study area are limited to latitude of $-3^{\circ}$ until $-17^{\circ}$ and longitude of $111.8^{\circ}$ until $112.8^{\circ}$.

After the data were downloaded, magnitudes of the earthquakes are converted to the same magnitude, i.e. moment magnitude (Mw) using empirical equation SNI 1726:2012 [9]. And then, the data were de-clustering to separate the main earthquake from the initial earthquake and aftershocks. The calculation stage of the magnitude

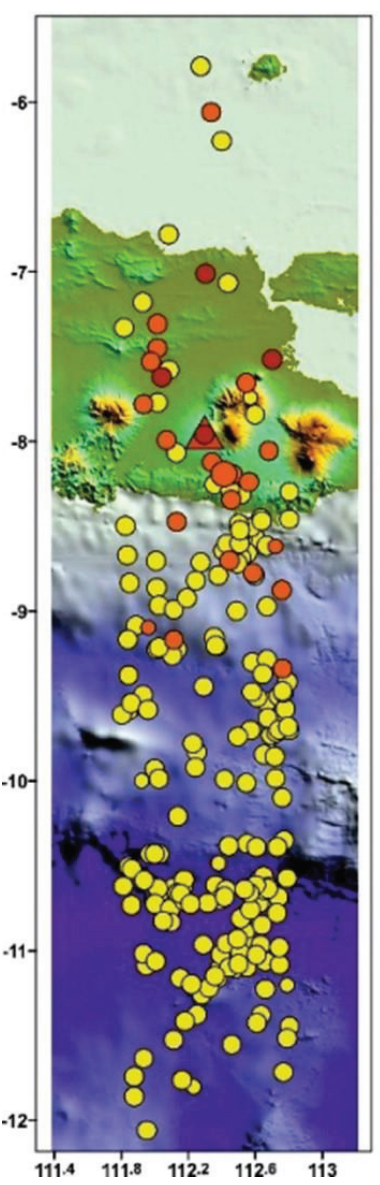

of completeness (Mc) is carried out to check the completeness of the tectonic data in general, before calculating the b-value. The Mc value is calculated using the Maximum-Curvature method by finding the maximum value of the first decrease in the frequencymagnitude distribution curve. Two earthquakes datasets (1990-2007 and 2008-2020) are then analyzed.

The b-value is obtained from the equation of the relationship between the magnitude and number of earthquakes formulated by [10], using linear equation:

$\log \mathrm{N}=\mathrm{a}-\mathrm{bM}$ (1),

with $\mathrm{N}$ is number of earthquake, $\mathrm{M}$ is earthquake magnitude, $\mathrm{a}$ and $\mathrm{b}$ are constants depending of number of earthquake event. High b-value in an area indicates brittle rock. Additionally, decreasing b-value indicates increasing critical failure stress [11].

\section{Results and discussion}

Figure 2 displays similar hypocentre distribution pattern between two earthquake datasets, i.e. deeper hypocentre to the north. Earthquakes with a hypocentre between 0 $100 \mathrm{~km}$ are predominantly in the ocean. In the contrary, earthquakes with a hypocentre of more than $100 \mathrm{~km}$ are predominantly on land.

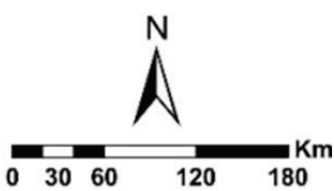

\section{Legend}

$\triangle$ Kelud volcano

Magnitude

$6.1-7$

○ $5.1-6$

○ 4.1 - 5

Depth $(\mathrm{Km})$

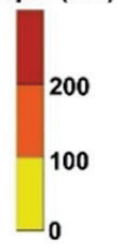

Fig. 2. Seismic events (circle) of the Kelud volcano (red triangle) and to the south until the Java trench. Left: from 1990-2007 earthquake dataset. Right: 2008-2020 earthquake dataset. 
Figure 2 also shows the epicentre of two earthquakes locating close to the Kelud volcano. The first earthquake was occurred in 2006 with a depth of $232 \mathrm{~km}$ and a magnitude of 5.2. The second earthquake was happened in 2011 with a hypocentre depth of $165 \mathrm{~km}$ and a magnitude of 5.4 .

For datasets 1990-2007 and 2008-2020; the b-value is 2.27 and 1.85 , respectively. The b-value resulted in this study is higher than the b-values as referred by [12] for many areas of the world. The $b=1.01$ as computed by [7] is smaller than our findings for dataset 19902007. For 2014-2019 data, the b-value 1.85 shows a decreasing (Figure 3).

Following [7], decreasing b-value around a volcano indicates accumulation of stress accompanied by instability of crack growth. From the temporal variation graph, it can be seen that at 2 different types of eruptions of the Kelud volcano, there are differences in the b-value of tectonic earthquakes. The b-value in the period of effusive eruption was greater than the period during the explosive eruption. This is probably related to the amount of energy that will be released. The same pattern of b-values also corresponds to the results of the study by [7], where the b-value before the explosive eruption in 1990 was smaller than the b-value before the effusive eruption in 2007.

The analysis of the $b$ value in time does not change immediately before an eruption $[3,7,8]$. Therefore, the $b$ value variations seem to be a long term precursor of the volcanic activity rather than a short precursor.

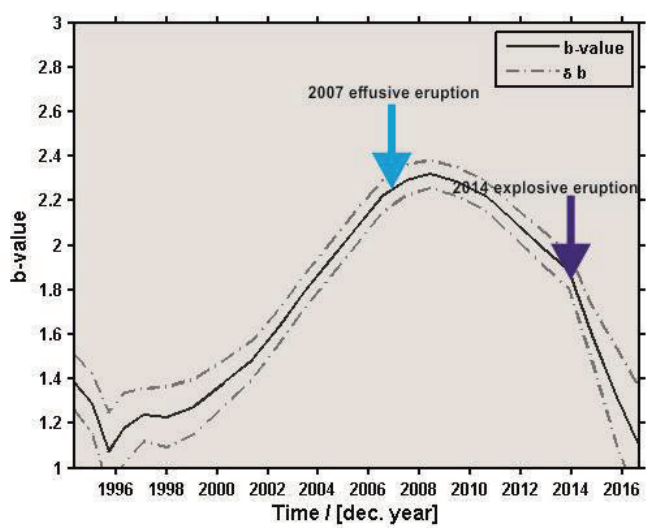

Fig. 3. B-value from 1990 until 2019 around Kelud volcano. Light blue arrow indicates when effusive eruption happened on 2007, while dark blue arrow points to explosive eruption on 2014. The explosive eruption on 2014 displays lower b-value compare to the effusive eruption on 2007.

A decrease in b-value is observed since 2009. It is possible that the decreases in b-value in this region result from small cracks due to change in the stress field near the magma chamber. In this way b-value calculations can give us more information about the physical process below the volcano. Given these findings we suggest that systematic evaluation of $b$-values become a more regular part of monitoring efforts. We also suggest analysing b-value using earthquakes data from local seismometer to double check and compare with b-value from earthquake data catalogue of USGS.

\section{Conclusion}

The b-value has been studied for earthquakes that occurred in the Kelud volcano region from 1990 to 2020. The b-value has been estimated that follows Gutenberg-Richter relationship. The b-values in 2007, when there was an effusive eruption, showed a value of 2.27, while in 2014 (when there was an explosive eruption) was 1.85 . This result is in good agreement with previous study that found the $b$-value before the explosive eruption in 1990 was smaller than the b-value before the effusive eruption in 2007.

Decreasing b-value after 2009 indicates there is accumulation stress below the volcano. This decrease likely reflects a combination of increased crack length due to the growth of small faults and cracks related to the 1990 and 2014 eruptions. As a long term precursor, $\mathrm{b}$-value variation is needed to calculate through time, as addition to volcano tectonic seismicity monitoring that gives short precursor.

The authors would like to thank to USGS for the data. We also want to thank to Faculty of Mathematics and Natural Sciences for the funding for this research.

\section{References}

1. S. Hidayati, H. Triastuty, I. Mulyana, S. Adi, K. Ishihara, A. Basuki, H. Kuswandarto, B. Priyanto, A. Solikhin, JVGR 382, 50-67 (2019)

2. R. Cas, J. Wright, Geological Magazine 125, 189200 (1988)

3. F. Maeno, S. Nakada, M. Yoshimoto, T. Shimano, N. Hokanishi, A. Zaenudin, M. Iguchi, JVGR 382, 24-41 (2019)

4. K. Aki, Bull Earthq Res Inst Tokyo Uni 43, 237239 (1965)

5. A. Kumar, S. Rai, A. Joshi, H. Mittal, R. Sachdeva, R. Kumar, V., Ghangas, Earthq Sci. 26(2), 99-105 (2013)

6. T. Hirata, T. Satoh, K. Ito, K, Geophys J R Astron Soc. 90, 369-374 (1987)

7. K. Brotopuspito, Wahyudi, Jurnal Berkala MIPA, 17, 3 (2007)

8. A. Mantovani, S. D'Amico, M. Barbano, The $b$ value as a long term precursor of volcanic activity: a case study at Mt. Etna, in Proceedings of the Convegno Nazionale GNGTS, November 2012, Potenza, Italy (2012)

9. M. Irsyam, M. Asrurifak, B. Hendriyawan, W. Triyoso, A. Firmanti, A., Geomech Geoengin Int J 5(1), 35-47 (2010)

10. B. Gutenberg F. Richter F., Seismicity of the Earth and its associated phenomenon (Princeton University Press. Princeton, 1954) 
11. S. Rao, K. Lakshmi, K., Current Science 89(9), 1582 (2005)

12. W. Lee, S. Stewart, Principles and application of micro-earthquake networks (Academic Press, New York, p 216, 1981) 